\title{
Simultaneous Presentation of Waldenström Macroglobulinemia and Multiple Myeloma: Multidisciplinary Diagnosis, Treatment and 30-Month Follow-up
}

\author{
Giovanni Carulli, ${ }^{1)}$ Eugenio M Ciancia, ${ }^{2)}$ Antonio Azzarà, ${ }^{1)}$ Virginia Ottaviano, ${ }^{1)}$ Susanna Grassi, ${ }^{1)}$ \\ Elena Ciabatti, ${ }^{1)}$ Maria I Ferreri, ${ }^{3)}$ Melania Rocco, ${ }^{1)}$ Alessandra Marini, ${ }^{4)}$ and Mario Petrini ${ }^{1)}$
}

Waldenström macroglobulinemia and multiple myeloma are mature B-cell neoplasms deriving from post-germinal cells at different stages of differentiation. The simultaneous presentation of Waldenström macroglobulinemia and multiple myeloma in the same patient is a very rare phenomenon and, so far, only two cases have been described. We report the case of a 75-year Caucasian female patient, with a silent clinical history, who presented with anemia and two different monoclonal proteins (IgM $\varkappa$ and $\operatorname{IgG} \varkappa$ ). The trephine biopsy showed the presence of a dual population, represented by small lymphoplasmacytoid cells and by plasma cells, which infiltrated the bone marrow with a clearly different pattern. Both immunohistochemistry and flow cytometry demonstrated the biclonal origin such neoplastic cells, since lymphoplasmacytoid cells resulted $\operatorname{IgM} \varkappa$ while plasma cells were IgG $x$. This biclonal pattern was further confirmed by the demonstration of a different $\operatorname{IgH}$ gene rearrangement of the two neoplasms. The patient was treated with bortezomib, dexamethasone and rituximab, achieving partial remission of both Waldenström macroglobulinemia and multiple myeloma. After a 30-month follow-up, she is in stable disease. Multiple myeloma has been described in association with other indolent B-cell neoplasms, mostly chronic lymphocytic leukemia, while Waldenström macroglobulinemia can be followed by diffuse large B-cell lymphoma in some instances, after chemotherapy. The association of Waldenström macroglobulinemia and multiple myeloma seems to be very rare. Our study shows that an integrated diagnostic work-up is very useful in such cases, with an interesting role for flow cytometry. $〔 J$ Clin Exp Hematop 53(1): 29-36, 2013]

Keywords: flow cytometry, immunohistochemistry, morphology, multiple myeloma, Waldenström macroglobulinemia

\section{INTRODUCTION}

Waldenström macroglobulinemia (WM) is a hematologic neoplasm characterized by a monoclonal lymphoplasmacytic expansion, with a variable plasma cell component and accompanied by a serum monoclonal immunoglobulin $\mathrm{M}(\operatorname{IgM}) .{ }^{1}$ It is an infrequent disease, accounting for approximately $2 \%$ of all hematologic malignant neoplasms, and shows a $2.8 \%$ frequency of association with other hematologic diseases. In these instances, acute myeloid leukemia and diffuse large Bcell lymphoma can occur, always being therapy-related. ${ }^{2}$

\footnotetext{
Received: October 21, 2012

Revised : December 10, 2012

Accepted : December 15, 2012

${ }^{1)}$ Division of Hematology, Department of Clinical and Experimental Medicine, University of Pisa, Italy

${ }^{2)}$ Second Division of Pathology and ${ }^{33}$ Laboratory of Cytogenetics, AOUP, Pisa, Italy

${ }^{4}$ Laboratory of Clinical Pathology, Versilia Hospital, Lido di Camaiore, Italy

Corresponding author : Giovanni Carulli, M.D., Division of Hematology, Santa Chiara

Hospital, Via Roma 67, 56126 Pisa, Italy.

E-mail : giovannicarulli@alice.it
}

So far, an association of WM with multiple myeloma (MM) has been reported in only two cases, ${ }^{3,4}$ and in a single case the evolution of WM into an aggressive form of IgMpositive multiple myeloma has been described. ${ }^{5}$

On the other hand, MM is a more frequent disease and is characterized by the proliferation of a single clone of plasma cells derived from B cells in the bone marrow and, in most cases, by the production of a monoclonal protein such as IgG, IgA or light chain only. ${ }^{6}$ Compared to WM, the association of MM with another B-cell lymphoproliferative disease has been reported in a higher number of cases. The simultaneous occurrence of MM and chronic lymphocytic leukemia (CLL) seems to be the most frequent event. Sometimes, CLL is discovered incidentally in patients with newly-diagnosed $\mathrm{MM},{ }^{7-9}$ while in other cases MM develops during the evolution of CLL. ${ }^{7,-12}$ In turn, CLL may also occur during the evolution of MM. ${ }^{13}$

The coexistence of MM with B-cell diseases other than CLL seems to be rarer, and occasional cases of metachronous or synchronous occurrence of MM with follicular 
lymphoma, ${ }^{14}$ malignant renal lymphoma, ${ }^{15}$ MALT lymphoma, ${ }^{16}$ and mantle cell lymphoma ${ }^{17}$ have been reported.

Therefore, because of the rarity of a combined presentation of WM and MM, we describe a case of a patient who presented with severe anemia, two different monoclonal proteins $(\operatorname{IgM} \varkappa$ and $\operatorname{IgG} \varkappa$ ) and evidence of simultaneous occurrence of $\operatorname{IgG} \varkappa \mathrm{MM}$ and WM. Diagnosis was made by combination of morphology with immunohistochemistry, flow cytometry and $\operatorname{IgH}$ gene rearrangement analysis. In the present paper we present the diagnostic work-up, results of therapy, a 30-month follow-up.

\section{CASE REPORT}

A Caucasian 75-year-olf female, with a silent clinical history, presented with anemia-related symptoms (fatigue and effort dyspnea). A complete blood count showed: $\mathrm{Hb} 9.3$ $\mathrm{g} / \mathrm{dL}$; white blood cell $5,71 \times 10^{9} / \mathrm{L}$ (differential: neutrophil $55 \%$, lymphocyte $35 \%$, monocyte $7 \%$, eosinophil $2.5 \%$, and basophil $0.5 \%$ ); platelets $271 \times 10^{9} / \mathrm{L}$. Chemistries showed: plasmatic protein $9.6 \mathrm{~g} / \mathrm{dL}, \beta_{2}$-microglobulin $8.5 \mathrm{mg} / \mathrm{L}$ (normal range $<2$ ), IgG $3,250 \mathrm{mg} / \mathrm{dL}$, IgA $55 \mathrm{mg} / \mathrm{dL}$, and IgM $1,380 \mathrm{mg} / \mathrm{dL}$. Serum protein electrophoresis showed $\gamma$ globulins $46.3 \%$ and an altered $\gamma$-globulin area morphology, with the apparent presence of two spikes (Fig. 1). Calcium concentrations were normal as well as creatinine concentrations. Serum immunofixation demonstrated the presence of two monoclonal proteins, one identified as $\operatorname{IgG} \varkappa$, the other as $\operatorname{IgM} \varkappa$. Urinary immunofixation was negative for monoclonal proteins. X-ray skeletal survey showed a few lytic areas involving femurs. No involvement of lymph nodes nor hepato-splenomegaly were found by whole body computed tomography and ultrasound sonography.

The patient underwent bone marrow evaluation by myeloaspirate and trephine biopsy. Samples from myeloaspirate were subjected to light microscope observation, flow cytometry, molecular tests for $\operatorname{IgH}$ gene rearrangement, karyotype

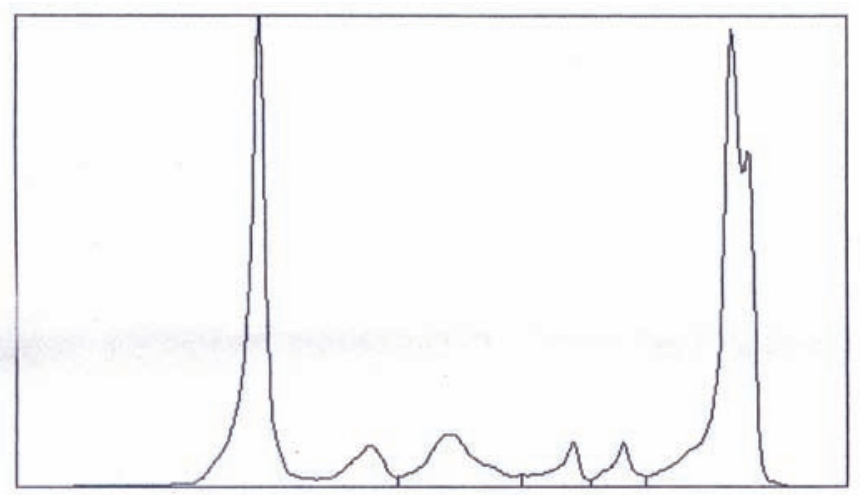

Fig. 1. Altered morphology of serum protein electrophoresis. The gamma region shows two different spikes. and fluorescent in situ hybridization (FISH) tests. Smears were stained by May-Grünwald-Giemsa and showed conspicuous infiltration (70\%) by lymphocytes and lymphoplasmacytoid cells, and the concomitant presence of plasma cells, which accounted for $10 \%$ of cellularity (Fig. 2).

Flow cytometric immunophenotyping of bone marrow samples was performed using a FacsCanto II cytometer (Becton Dickinson) equipped with three lasers (405, 488 and $633 \mathrm{~nm})$. Samples $(50 \mu \mathrm{L})$ were stained with fluorochromeconjugated monoclonal antibodies (MoAbs) specific for the following antigens: $\mathrm{CD} 5, \mathrm{CD} 8, \mathrm{CD} 10, \mathrm{CD} 11 \mathrm{c}, \mathrm{CD} 16$, CD19, CD20, CD22, CD23, CD25, CD27, CD38, CD45, CD56, CD81, CD103, CD117, CD138, (purchased from Becton Dickinson), rabbit $\mathrm{F}(\mathrm{ab})_{2}$ polyclonal antibodies directed to $\gamma$ and $\mu$ immunoglobulin heavy chains and $\varkappa$ and $\lambda$ immunoglobulin light chains (purchased from Dako). A multiparametric method with either seven or eight fluorescences was used for each tube, associating MoAbs conjugated with FITC, PE, PerCP-Cy5.5, PE-Cy.7, APC, APC-Cy.7, AmCyan and Pacific Blue. Lymphocytes were gated using CD45 expression and right angle scatter, and at least 100,000 events/ tube were acquired. A second gate included $\mathrm{CD} 19^{+}$events and was used to analyze the expression of the other markers. Plasma cells were identified by the CD38/CD138 combination, acquiring 500,000 events/tube. A second gate was set to analyze events with homogeneous forward scatter and side scatter (SSC) properties, and was used to analyzed the expression of the other markers eventually associated with plasma cells (CD10, CD20, CD27, CD56, CD81, and CD117). ${ }^{18,19}$

Immunophenotyping showed infiltration by two neoplastic clones. The former was predominant $(60 \%)$ and consisted

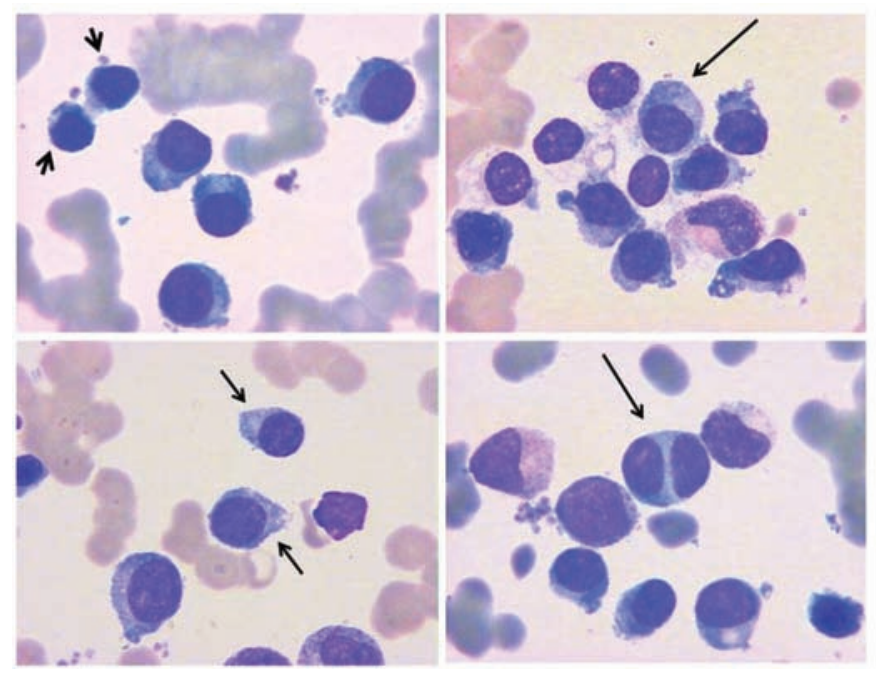

Fig. 2. Myeloaspirate at diagnosis showing infiltration by lymphocytes, plasmacytoid lymphocytes and plasma cells $(\times 1,000)$. Some plasma cells (the longest arrows), plasmacytoid lymphocytes (intermediate arrows) and lymphocytes (the shortest arrows) are shown. 
of B lymphocytes $\left(\mathrm{CD} 19^{+}\right.$and $\left.\mathrm{CD} 20^{+}\right)$with restriction for $\mu$ heavy chains and $\varkappa$ light chains, and without CD27 expression (Fig. 3). The latter was represented by atypical plasma cells $\left(\mathrm{CD} 38^{+}, \mathrm{CD} 138^{+}, \mathrm{CD} 19^{-}\right.$, and $\left.\mathrm{CD} 45^{-}\right)$, which accounted for $10 \%$ of cellularity and were negative for CD10, CD20, CD27, CD56, CD81, and CD117, with restriction for cytoplasmic $\gamma$ heavy chains and cytoplasmic $x$ light chains (Fig. 4A-4E). As a final result, neoplastic lymphocytes and MM plasma cells were found in different areas of CD45/SSC dot-plot (Fig. 4F). In our samples plasma cells belonging to the neoplastic clone of WM were not found, since the entire $\mathrm{CD} 38^{+} / \mathrm{CD} 138^{+}$cell population displayed features consisting with the MM pheno-
A

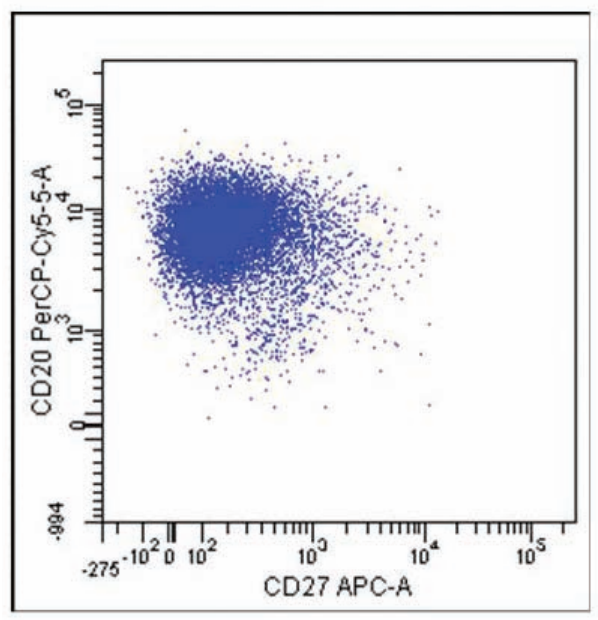

B

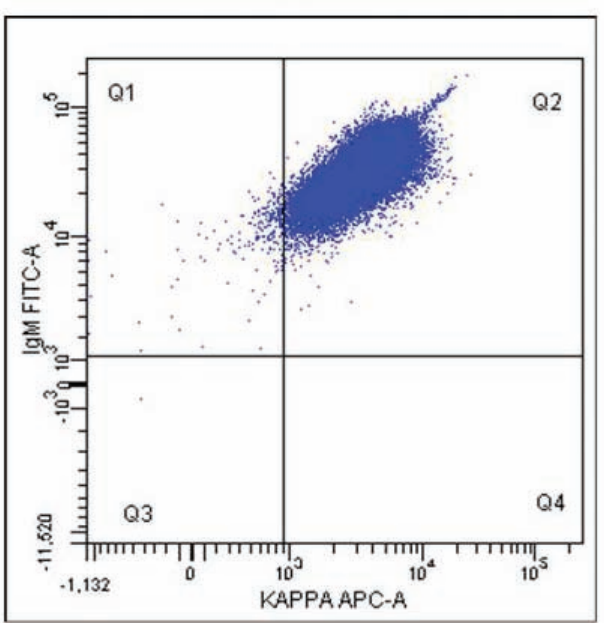

Fig. 3. Immunophenotyping of bone marrow lymphocytes after CD19 gating. B-cells show bright expression of CD20, negativity for CD27 (3A), and restriction for $\mu$ heavy chain and $\varkappa$ light chain $(3 B)$.

A

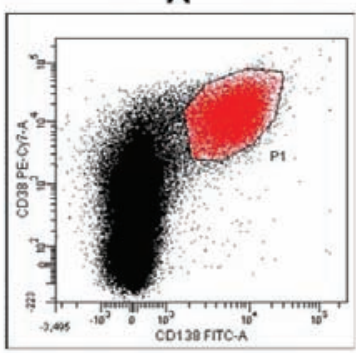

D

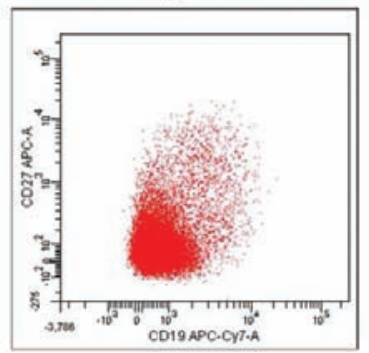

B

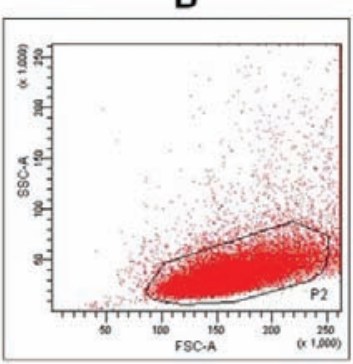

E

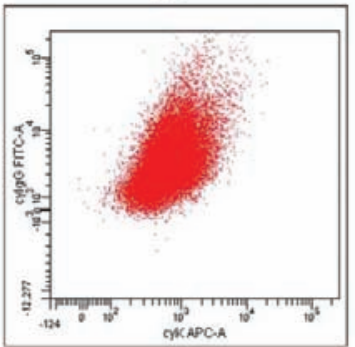

C

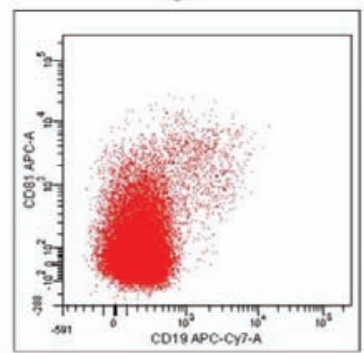

$\mathbf{F}$

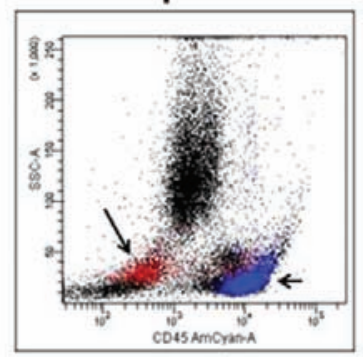

Fig. 4. Immunophenotyping of bone marrow plasma cells. (4A) CD38/CD138 gating. (4B) forward scatter/side scattergating. (4C-4E) Abnormal phenotype (negative for CD19, CD27, and CD81) and restriction for $\gamma$ heavy chain and $\varkappa$ light chain. (4F) multiple myeloma plasma cells (long arrow, red dots) and Waldenström macroglobulinemia lymphocytes (short arrow, blue dots) occupy different areas of CD45/side scatter dot-plot. 
type.

Bone marrow trephines were fixed in Myelodec ${ }^{\circledR}$ reagent A (Bio-Optica) for $2 \mathrm{hr}$, decalcified, embedded in paraffin, and cut into 3-5 $\mu \mathrm{m}$ sections. Morphological evaluations were carried out on hematoxylin-eosin, Giemsa, and GordonSweet for reticulin-stained sections. Immunohistochemical stainings were performed using a peroxidase-based system including antibodies specific for CD3/PS1, CD5/4C7, CD20/L6, CD23/1B12, CD138/B-A38, bc12/100-D5, bcl6/PG-B6p, and cyclin-D1 (DSC-6), and polyclonal antibodies directed to immunoglobulin $\gamma$ and $\mu$ heavy chains, and $\varkappa$ and $\lambda$ light chains. A BenchMark automated Slide Stainer (Ventana) was used.

The trephine biopsy showed a typical packed marrow with very high cellularity (90\%) (Fig. 5A) and with diffuse/interstitial infiltrate of two morphologically distinct cell populations. The intertrabecular spaces were mostly filled by small B cells (Fig. 5B), which were about $70 \%$ of cellularity. These neoplastic cells showed lymphoplasmacytoid morphology with numerous Dutcher bodies, and were associated with small plasma cells; both lymphoid cells and plasma cells showed immunoreactivity for $\mu$ heavy chain (Fig. 5C).

A distinct plasma cell population, accounting for about $15 \%$ of cellularity, was found and consisted of $\mathrm{CD} 138^{+}$plasma cells, which were CD20- (Fig. 5D), showed restriction for cytoplasmic $\lambda$ heavy chains (Fig. 5E) and were organized in small clusters. Both $\gamma$ chain $^{+}$plasma cells and $\mu$ chain ${ }^{+}$lymphoplasmacytoid cells stainedmonotypically for $\varkappa$ light chains (Fig. 5F).

$\mathrm{IgH}$ gene rearrangement analysis was performed on DNA extracted from bone marrow mononuclear cells separated by Ficoll/ Hypaque. Fluorescent polymerase chain reaction (PCR) was performed using $\mathrm{VH}$ region primer and CDR3/JH consensus primers 5 ' labeled with 6-FAM fluorochromes. ${ }^{20,21}$ The PCR products were tested by capillary electrophoresis on an automatic sequencer (ABI PRISM 3100) and analysed with GeneMapper 4.0 software, obtaining accurate sizing and quantification of the peak areas. This allows accurate predic- tion of the equivalence point of PCR products with $10^{-4}-10^{-5}$ sensitivity of molecular assays. The samples were also analysed for FR1 region to confirm the specific rearrangements. Reaction mixtures were prepared using the same JH consensus primer, with seven $\mathrm{VH}$ region family-specific primers. ${ }^{22}$
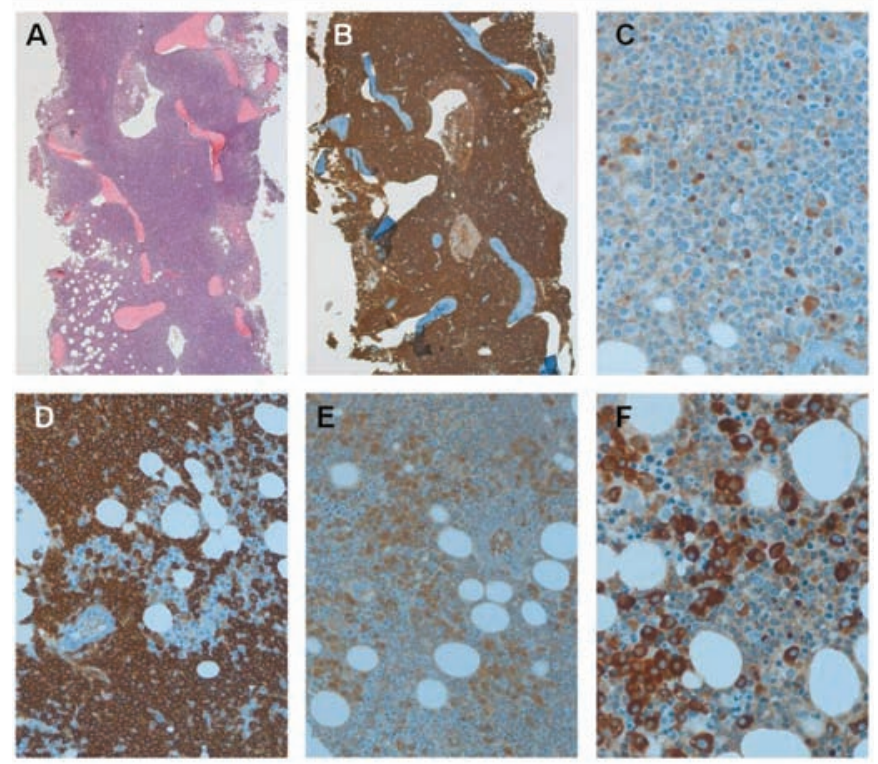

Fig. 5. Histology and immunohistochemical analysis of the bone marrow biopsy at diagnosis. (5A) Hematoxylin-eosin stain: markedly increase cellularity. $\times 40$. $(\boldsymbol{5 B}) \mathrm{CD} 20$ immunostain: the intertrabecular spaces are mostly filled by small B cells. $\times 40$. $(5 C)$ IgM immunostain: the neoplastic cells show lymphoplasmacytoid morphology with numerous Dutcher bodies, and are associated with small plasma cells; both lymphoid cells and small plasma cells show immunoreactivity for $\mu$ heavy chain. $\times 50$. (5D) The CD20 immunostaining is patchy, moth-eaten. Larger plasma cells, which are CD20-negative, tend to form aggregates or clusters. $\times 250$. $(\boldsymbol{5} \boldsymbol{E}) \mathrm{IgG}$ immunostain: plasma cells express $\gamma$ heavy chain. $\times 250$. $(\mathbf{5 F}) \varkappa$ light chain immunostaining: plasma cells and lymphoplasmacytoid cells both stain monotypically for mlight chain. $\times 250$.
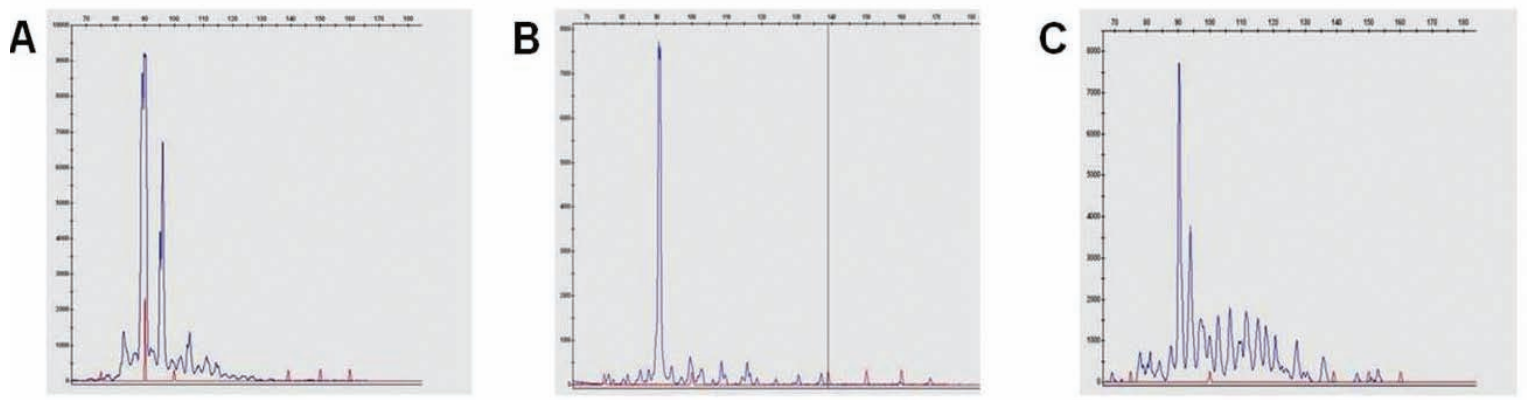

Fig. 6. Polymerase chain reaction assays for $I g H$ gene rearrangement. (6A) Two different clonal rearrangements can be seen at diagnosis. ( $6 \boldsymbol{B})$ A single clonal rearrangement is observed at the end of therapy. (6C) The second clonal rearrangement re-appears at the end of 30-month follow-up. 
PCR products were assessed by electrophoresis on a $2,5 \%$ agarose gel (about $350 \mathrm{bp}$ ). Two different monoclonal rearrangements of $\operatorname{IgH}$ were detected by both PCR (Fig. 6A) and gel electrophoresis (not shown). Unfortunately, it was not possible to study light immunoglobulin gene rearrangement.

Karyotyping, carried out by conventional G-banding methods, showed normal 46,XX, and FISH with probes for $17 \mathrm{p} 53,14 \mathrm{q} 32$ and $13 \mathrm{q} 14.3$ resulted negative. At the end of workup, a final diagnosis of WM associated with $\mathrm{IgG} \varkappa \mathrm{MM}$ was made.

Our patient underwent therapy with combination of bortezomib, dexamethasone and rituximab, according to the following schedule: bortezomib, i.v., weekly at $1.6 \mathrm{mg} / \mathrm{m}^{2}$ on days $1,8,15$, and 28 days $\times 8$ cycles; rituximab, $375 \mathrm{mg} / \mathrm{m}^{2}$ weekly on cycles 1 and 4; dexamethasone, $20 \mathrm{mg}$ on the day of and on the day after bortezomib. Because of severe reactions, the second rituximab course was not entirely administered.

As a result, a progressive reduction of total proteinemia, IgG and IgM levels was observed (Fig. 7), along with progressive increase in $\mathrm{Hb}$ values. At the end of treatment, complete response of MM (i.e. no M-protein detected in serum or urine by immunofixation for a minimum of 6 weeks and fewer than $5 \%$ plasma cells in bone marrow, absence of phenotypically abnormal bone marrow plasmacells) according

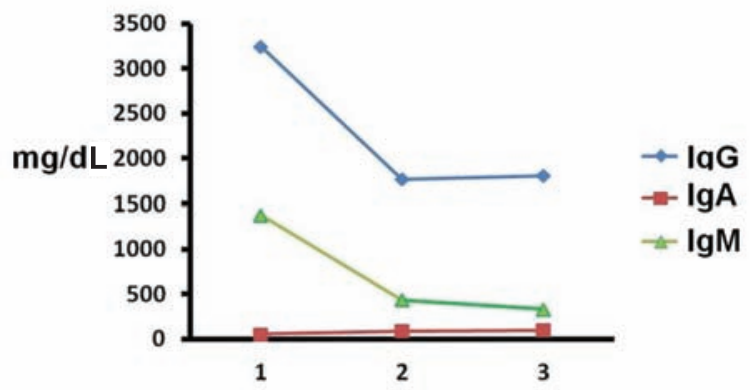

Fig. 7. $\operatorname{IgG}, \operatorname{IgA}$ and $\operatorname{IgM}$ behavior at diagnosis (1), after therapy (2) and at the end of follow-up (3). to the guide-lines published by the Haemato-oncology Task Force of the British Committee for Standards in Haematology $(\mathrm{BCSH})$ and UK Myeloma Forum, ${ }^{23}$ was obtained.

As far as the WM component is concerned, partial response was obtained, according to response criteria by the Third International Workshop on Waldenström's macroglobulinemia, ${ }^{24}$ with $\mathrm{IgM}^{+}$immunofixation, IgM 370 $\mathrm{mg} / \mathrm{dL}$, persistence of $30 \%$ of $\mathrm{IgM} / \varkappa^{+}$lymphocytes (bone marrow biopsy).

Protidogram showed a mild, single monoclonal band of $\gamma$ globulins, and the PCR assay form $\operatorname{IgH}$ gene rearrangement showed a unique clonal band (Fig. 6B). At the time of submission (30-mon follow-up) of the present paper, IgM levels were $400 \mathrm{mg} / \mathrm{dL}$, but recurrence of $\mathrm{MM}$ was observed with immunofixation positive for $\mathrm{IgG} / \varkappa$ and $1,810 \mathrm{mg} / \mathrm{dL} \mathrm{IgG}$. Protidogram appeared very similar to that of presentation (not shown). The new histological examination of bone marrow showed $30 \%$ neoplastic lymphocytes and $10 \%$ clonal plasma cells. Immunophenotyping showed a low amount $(20 \%)$ of clonal lymphocytes along with 3\% immunophenotypically abnormal and clonal plasma cells (Fig. 8). PCR for $I g H$ gene rearrangement was again characterized by two distinct clonal peaks (Fig. 6C). Therefore, after a 30-mon follow-up, a good control of disease was achieved, with our patient feeling well.

\section{DISCUSSION}

The association, either synchronous or metachronous, of two different B-cell lymphoproliferative diseases can be detected in few cases and CLL seems the most frequent disease which can occur with MM. This phenomenon is very interesting because the clonal relationship of MM and a concomitant B-cell disease is a matter of debate. In few instances, a derivation from a single B-cell precursor has been suggested by the demonstration of identical $\operatorname{IgH}$ gene rearrangements, but opposite results were found in most cases and biclonal origin prevails. ${ }^{25}$

Interesting epidemiologic studies carried out in the past

\section{Lymphocytes}

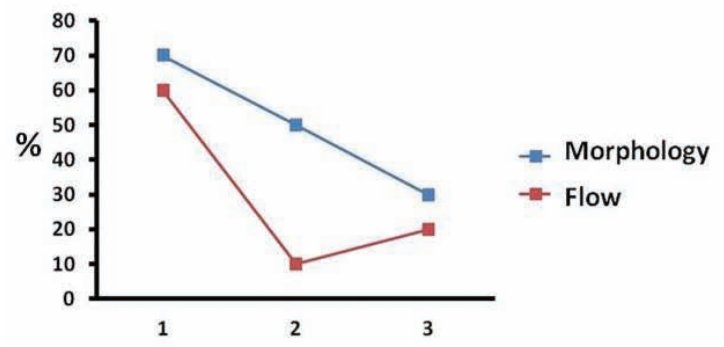

Plasma cells

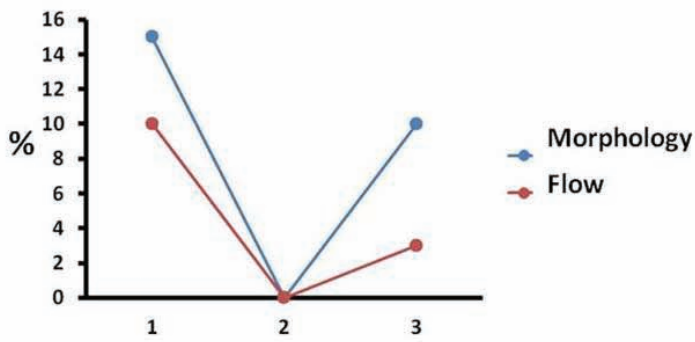

Fig. 8. Percentages of bone marrow lymphocytes and plasma cells measured by morphology (trephine biopsy) and flow cytometry at diagnosis (1), after therapy (2), and at the end of follow-up (3). 
have shown that patients with MM, enrolled in the Swedish Cancer Registry, had a slight increase in standardized incidence ratio for non-Hodgkin lymphomas in the period 1 to 9 years after diagnosis. ${ }^{26}$ A similar study carried out in Japan between 1962 and 1996 did not show any significant incidence of association of MM and lymphoma, either synchronous or metachronous. ${ }^{27}$ Thus, the detection of non-Hodgkin lymphoma at the time of diagnosis of MM should be considered an infrequent event and represents an interesting biological phenomenon.

As far as WM is concerned, its association with MM seems to be a very rare phenomenon and only two cases have been reported so far. In the first one, described by Fine et al. in $1981^{3}$ and concerning a patient with biclonal gammopathy $\operatorname{IgM} \varkappa$ and $\operatorname{IgG} \lambda$, MM was detected in bone marrow sections and WM in lymph node aspirations. Flow cytometric and molecular assays were not available. In the second case, describedin 2012 by Wang E, et al., ${ }^{4}$ a patient developed a sequential development of WM and plasmablastic IgA multiple myeloma over a 10-year period of untreated IgM gammopathy. Another, but very rare possibility, is represented by evolution of WM into an IgM-producing MM. ${ }^{5}$

In our case, an old female without a significant clinical history presented with anemia-related symptoms and with the presence of two monoclonal proteins, $\operatorname{IgM} \varkappa$ and $\operatorname{IgG} \varkappa$, which were suggestive of twodifferent neoplastic clones. Flow cytometry, carried out by a wide MoAb panel able to detect both plasmacells and lymphocytes, showed the co-existence of two different abnormal clones. B-lymphocytes $\left(\mathrm{CD} 19^{+}\right.$and $\mathrm{CD} 20^{+}$) showed restriction for $\gamma$ heavy chain and for $\varkappa$ light chain, and resulted to be CD27-negative. Plasma cells, identified by the classical $\mathrm{CD} 138^{+} / \mathrm{CD} 38^{+}$combination, were characterized by an abnormal phenotype (being $\mathrm{CD} 19^{-}, \mathrm{CD} 27^{-}$, and $\mathrm{CD}^{-} 1^{-}$) and by positivity for intracytoplasmic $\gamma$ heavy chain and $\varkappa$ light chain.

Morphology and immunohistochemistry, carried out on sections obtained from trephine biopsy, confirmed the peculiar association of WM and MM. Infiltration by lymphocytes and lymphoplasmacytoid cells, attributable to WM, showed a diffuse/interstitial pattern which characterizes a high percentage of WM cases, ${ }^{28}$ while the neoplastic plasma cell population attributable to MM infiltrated the bone marrow in a different way, focally forming confluent aggregates. It is known that plasma cell in WM are usually morphologically mature and are generally mixed with the predominant lymphocytic population. Small perisinusoidal clusters can sometimes be found, but their infiltration patter is quite different from that shown by MM plasma cells. ${ }^{1}$

The biclonal nature of these populations was further supported by immunohistochemistry because, although both MM and WM were restricted to $x$ light chain, a divergent positivity for $\mu$ and $\gamma$ heavy chains was found. In addition, the molecular analysis of IgH gene confirmed the presence of two dis- tinct clonal rearrangements, clearly deriving from two different neoplastic clones. Both immunophenotypic and morphologic findings were in agreement with the initial diagnostic suspect of an association of MM and WM. The above findings seem to exclude a common clonal origin of the two neoplastic clones, and are consistent with a distinct clonal progenitor.

WM is likely to develop from a post-germinal memorylike B cell that has undergone somatic hypermutation but not isotype switching, and is able to acquire a lymphoplasmacytoid phenotype and IgM secretory capacity. ${ }^{29,30}$ In addition, the neoplastic B-cells of WM show the phenotype of $\mathrm{CD} 27^{-}$ memory B-cells. The absence of CD27 on the surface of Bcells seems to be a typical feature of WM and is likely to depend on shedding from cell surface, since the neoplastic burden has been found to correlate with soluble CD27 concentrations. ${ }^{31}$ Lymphoplasmacytoidcells of WM retain expression of mature B-cell markers, such as CD20 and surface $\mathrm{IgM},{ }^{32}$ which are normally lost in healthy plasmablasts and plasma cells. On the contrary, myelomatous plasma cells are $\mathrm{CD} 19^{-}$and/or $\mathrm{CD}^{-} 5^{-}$, with rare exceptions, and often lack CD27 and CD81. Other B-cell-associated markers (CD10 and CD20) are positive in very low percentage of cases. ${ }^{18,33}$

Although both MM and WM tend to occur in the elderly, compared to MM, WM is rare. In fact, data from the US Surveillance, Epidemiology and End Results (SEER) Registry estimate the incidence of WM to be 0.36 per 100,000 personsyear, ${ }^{34}$ a rate that is less than one-tenth that of MM (6 per 100,000 in Europe). ${ }^{35}$ Therefore, the probability that the two diseases could occur simultaneously is very low and seems the justify the rarity of such an event.

We chose to treat our patient with a schedule which included bortezomib, dexamethasone and rituximab. Unfortunately, rituximab was not tolerated, and its administration was incomplete. Nevertheless, the efficacy of therapy was good and an acceptable control of both WM and MM was achieved. Indeed, the combination of weekly bortezomib and rituximab exhibited significant activity in untreated patients with $\mathrm{WM},{ }^{36}$ and the association of bortezomib and dexamethasone has been employed as first line therapy in patients with MM. ${ }^{37,38}$ Therefore, we used a hybrid therapy schedule in an attempt to control both WM and MM.

Another interesting aspect of our observation is represented by the application of flow cytometry in the diagnostic approach of such a clinical case. Some interesting papers have shown that the neoplastic clone of WM can be identified by multiparameter flow cytometry, despite the lack of a specific immunophenotype. ${ }^{32,39} \mathrm{We}$ found that the combination of IgM clonality and lack of CD27 seems to improve diagnosis and in our case such interpretation was found to correlate with morphology. Indeed, very recent observations ${ }^{40}$ demonstrate that in WM flow cytometry yields results comparable to morphology with immunohistochemistry and that using both 
techniques in parallel improves diagnosis.

In conclusion, the current contribution shows that rare cases of co-existence of MM and WM may occur and that an integrated diagnostic approach, based on the simultaneous usage of morphology, and flow cytometry and molecular assays is able to facilitate the recognition of such peculiar disease association. The therapeutic schedule used in our patient, which and allowed to obtain a good control of both $\mathrm{WM}$ and $\mathrm{MM}$, might be used in further cases.

\section{REFERENCES}

1 Vijay A, Gertz MA: Waldenström macroglobulinemia. Blood 109:5096-5103, 2007

2 Hanzis C, Ojha RP, Hunter Z, Manning R, Lewicki M, et al.: Associated malignancies in patients with Waldenström's macroglobulinemia and their kin. Clin Lymphoma Myeloma Leuk 11: 88-92, 2011

3 Fine JM, Gorin NC, Gendre JP, Petitpierre JC, Labro-Bryskier MT, et al:: Simultaneous occurrence of clinical manifestations of myeloma and Waldenström's macroglobulinemia with monoclonal IgGo and IgM in a single patient. Acta Med Scand 209:229234, 1981

4 Wang E, Kulbacki E, Stoecker M: Concomitant Waldenström macroglobulinemia and IgA plasmablastic myeloma in a patient with untreated IgM paraproteinemia: sequential development of biclonal B-cell neoplasms over a 10 -year period in a single individual. Hum Pathol 43:1135-1141, 2012

5 Jondeau K, Alterescu R, Franc B, Davi F, Massé JM, et al.: Unusual evolution of Waldenström's macroglobulinemia into osteolytic myeloma. Eur J Haematol 77:74-79, 2006

6 Kyle RA, Rajkumar SV: Criteria for diagnosis, staging, risk stratification and response assessment of multiple myeloma. Leukemia 23:3-9, 2009

7 Brouet JC, Fermand JP, Laurent G, Grange MJ, Chevalier A, et al.: The association of chronic lymphocytic leukaemia and multiple myeloma: a study of eleven patients. Br J Haematol 59:55-66, 1985

8 Saltman DL, Ross JA, Banks RE, Ross FM, Ford AM, et al:: Molecular evidence for a single clonal origin in biphenotypic concomitant chronic lymphocytic leukemia and multiple myeloma. Blood 74:2062-2065, 1989

9 Novak PM, Mattson JC, Crisan D, Chen J, Poulik MD, et al.: Separate clones in concomitant multiple myeloma and a second Bcell neoplasm demonstrated by molecular and immunophenotypic analysis. Eur J Haematol 54:254-261, 1995

10 Pines A, Ben-Bassat I, Selzer G, Ramot B: Transformation of chronic lymphocytic leukemia to plasmacytoma. Cancer 54:19041907, 1984

11 Yahata N, Iwase O, Iwama H, Tauchi T, Kawanishi Y, et al.: Chronic lymphocytic leukemia complicated by plasmacytoma originating from different clones. Leuk Lymphoma 39:203-207, 2000
12 Patriarca F, Gaidano G, Capello D, Zaja F, Fanin R, et al.: Occurrence of multiple myeloma after fludarabine treatment of a chronic lymphocytic leukemia: evidence of a biclonal derivation and clinical response to autologous stem cell transplantation. Haematologica 85:982-985, 2000

13 Zalcberg JR, Cornell FN, Ireton HJ, McGrath KM, McLachlan R, et al.: Chronic lymphatic leukemia developing in a patient with multiple myeloma: immunologic demonstration of a clonally distinct second malignancy. Cancer 50:594-597, 1982

14 Yakushijin Y, Sakai I, Takada K, Yasukawa M, Fujita S: Double B-cell malignancies with simultaneous onset. Rinsho Ketsueki 45: 218-222, 2004 (in Japanese)

15 Hayakava M, Asano T, Nakajima F, Tamai S, Nakamura H: Simultaneous presentation of malignant lymphoma of the kidney and multiple myeloma of the bone marrow. Int J Urol 5:374-376, 1998

16 Wöhrer S, Raderer M, Streubel B, Chott A, Drach J: Concomitant occurrence of MALT lymphoma and multiple myeloma. Ann Hematol 83:600-603, 2004

17 Wang YI, Karandikar N, Payne D, Maleki A, Schultz BA, et al.: A 3-way collision tumor of the upper respiratory tract: a composite of 2 immunophenotypically distinct mantle cell lymphomas and a plasmacytoma. Hum Pathol 39:781-787, 2008

18 Rawstron AC, Orfao A, Beksac M, Bezdickova L, Brooimans RA, et al.: Report of the European Myeloma Network on multiparametric flow cytometry in multiple myeloma and related disorders. Haematologica 93:431-438, 2008

19 Carulli G, Cannizzo E, Ottaviano V, Cervetti G, Buda G, et al.: Abnormal phenotype of bone marrow plasma cells in patients with chronic myeloid leukemia undergoing therapy with Imatinib. Leuk Res 34:1336-1339, 2010

20 Reed TJ, Reid A, Wallberg K, O’Leary TJ, Frizzera G: Determination of B-cell clonality in paraffin-embedded lymphnodes using the polymerase chain reaction. Diagn Mol Pathol 2:42-49, 1993

21 Ritter JH, Wick MR, Adesokan PN, Fitzgibbon JF, Zhu X, et al.: Assessment of clonality in cutaneous lymphoid infiltrates by polymerase chain reaction analysis of immunoglobulin heavy chain gene rearrangement. Am J Clin Pathol 108:60-68, 1997

22 Zwicky CS, Maddocks AB, Andersen N, Gribben JG: Eradication of polymerase chain reaction detectable immunoglobulin gene rearrangement in non-Hodgkin's lymphoma is associated with decreased relapse after autologous bone marrow transplantation. Blood 88:3314-3322, 1996

23 Bird JM, Owen RG, D'Sa S, Snowden JA, Pratt G, et al.: Guidelines for the diagnosis and management of multiple myeloma 2011. Br J Haematol 154:32-75, 2011

24 Kimby E, Treon SP, Anagnostopoulos A, Dimopoulos M, GarciaSanz R, et al.: Update on recommendations for assessing response from the Third International Workshop on Waldenström's Macroglobulinemia. Clin Lymphoma Myeloma 6:380-383, 2006

25 Pantic M, Schroettner P, Pfeifer D, Rawluk J, Denz U, et al.: Biclonal origin prevails in concomitant chronic lymphocytic leu- 


\section{Carulli G, et al.}

kemia and multiple myeloma. Leukemia 24:885-890, 2010

26 Dong C, Hemminki K: Second primary neoplasms among 53159 haematolymphoproliferative malignancy patients in Sweden, 1958-1996: a search for common mechanisms. Br J Cancer 85:997-1005, 2001

27 Kaneko S, Yamaguchi N: Epidemiological analysis of site relationships of synchronous and metachronous multiple primary cancers in the National Cancer Center, Japan, 1962-1996. Jpn J Clin Oncol 29:96-105, 1999

28 Owen RG, Barrans SL, Richards SJ, O’Connor SJ, Child JA, et al.: Waldenström macroglobulinemia. Development of diagnostic criteria and identification of prognostic factors. Am J Clin Pathol 116:420-428, 2001

29 McMaster ML, Caporaso N: Waldenström macroglobulinaemia and $\operatorname{IgM}$ monoclonal gammopathy of undetermined significance: emerging understanding of a potential precursor condition. Br J Haematol 139:663-671, 2007

30 Stone MJ, Pascual V: Pathophysiology of Waldenström's macroglobulinemia. Haematologica 95:359-364, 2010

31 Ciccarelli BT, Yang G, Hatjiharissi E, Ioakimidis L, Patterson CJ, et al:: Soluble CD27 is a faithful marker of disease burden and is unaffected by the rituximab-induced IgM flare, as well as by plasmapheresis, in patients with Waldenström's macroglobulinemia. Clin Lymphoma Myeloma 9:56-58, 2009

32 Konoplev S, Medeiros LJ, Bueso-Ramos CE, Jorgensen JL, Lin P: Immunophenotypic profile of lymphoplasmacytic lymphoma/ Waldenström macroglobulinemia. Am J Clin Pathol 124:414-420, 2005

33 Bataille R, Jégo G, Robilard N, Barillé-Nion S, Moreau P, et al.: The phenotype of normal, reactive and malignant plasma cells.
Identification of "many and multiple myelomas" and of new targets for myeloma therapy. Haematologica 91:1234-1240, 2006

34 Groves FD, Travis LB, Devesa SS, Ries LA, Fraumeni JF Jr: Waldenström's macroglobulinemia: incidence patterns in the United States, 1988-1994. Cancer 82:1078-1081, 1998

35 Ludwig H, Bolejack V, Crowley J, Bladé J, Miguel JS, et al.: Survival and years of life lost in different age cohorts of patients with multiple myeloma. J Clin Oncol 28:1599-1605, 2010

36 Ghobrial IM, Xie W, Padmanabhan S, Badros A, Rourke M, et al.: Phase II trial of weekly bortezomib in combination with rituximab in untreated patients with Waldenström macroglobulinemia. Am J Hematol 85:670-674, 2010

37 Jagannath S, Durie BG, Wolf J, Camacho E, Irwin D, et al.: Bortezomib therapy alone and in combination with dexamethasone for previously untreated symptomatic multiple myeloma. Br J Haematol 129:776-783, 2005

38 Kumar SK, Mikhael JR, Buadi FK, Dingli D, Dispenzieri A, et al.: Management of newly diagnosed symptomatic multiple myeloma: updated Mayo Stratification of Myeloma and Risk-Adapted Therapy (mSMART) consensus guidelines. Mayo Clin Proc 84:1095-1110, 2009

39 Morice WG, Chen D, Kurtin PJ, Hanson CA, McPhail ED: Novel immunophenotypic features of marrow lymphoplasmacytic lymphoma and correlation with Waldenström's macroglobulinemia. Mod Pathol 22:807-816, 2009

40 Howard MT, Hodnefield J, Morice WG: Immunohistochemical phenotyping of plasma cells in lymphoplasmacytic lymphoma/ Waldenström's macroglobulinemia is comparable to flow cytometric techniques. Clin Lymphoma Myeloma Leuk 11:96-98, 2011 